\title{
Investigation on Nano-Self-Lubricant Coating Synthesized by Laser Cladding and Ion Sulfurization
}

\author{
Meiyan Li, ${ }^{1}$ Bin Han, ${ }^{1}$ Conghua Qi, ${ }^{1}$ Yong Wang, ${ }^{1}$ and Lixin Song ${ }^{2}$ \\ ${ }^{1}$ College of Electromechanical Engineering, China University of Petroleum, 66 ChangJiang West Road, Qingdao 266580, China \\ ${ }^{2}$ Offshore Oil Engineering (Qingdao) Co., Ltd., Qingdao 266520, China \\ Correspondence should be addressed to Meiyan Li; limeiyan@upc.edu.cn
}

Received 5 January 2015; Accepted 13 March 2015

Academic Editor: Quanshun Luo

Copyright (c) 2015 Meiyan Li et al. This is an open access article distributed under the Creative Commons Attribution License, which permits unrestricted use, distribution, and reproduction in any medium, provided the original work is properly cited.

\begin{abstract}
The composite processing between laser cladding and low temperature $\left(300^{\circ} \mathrm{C}\right)$ ion sulfurization was applied to prepare wear resistant and self-lubricating coating. The microstructure, morphology, phase composition, valence states, and wear resistance of the composite coating were investigated by scanning electron microscopy (SEM), atomic force microscope (AFM), X-ray diffraction (XRD), X-ray photoelectron spectroscope (XPS), and friction and wear apparatus. The results indicate that the laser cladding Nibased coatings and the maximum hardness of $46.5 \mathrm{HRC}$ were obtained when the percent of pure $\mathrm{W}$ powder was $10 \%$, composed of columnar dendrites crystals and ultrafine dendritic structure. After ion sulfurization at $300^{\circ} \mathrm{C}$ for $4 \mathrm{~h}$, the loose and porous composite coating is formed with nanograins and the granularity of all grains is less than $100 \mathrm{~nm}$, which consists of $\gamma$-(Fe, Ni), $\mathrm{M}_{23} \mathrm{C}_{6}$ carbides, $\mathrm{FeS}, \mathrm{FeS}_{2}$, and $\mathrm{WS}_{2}$. Furthermore, the wear resistance of the composite coating is better than the laser cladding $\mathrm{Ni} 55+10 \% \mathrm{~W}$ coating, and the friction coefficient and mass losses under the conditions of dry and oil lubrication are lower than those of laser cladding Ni55 $+10 \% \mathrm{~W}$ coating.
\end{abstract}

\section{Introduction}

In order to improve the wear resistance of the key parts, in recent years advanced rapid solidification technologies such as laser surface processing [1-4], thermal spraying [5], and plasma spraying [6-8] have been reported to be feasible routes for enhancing the surface properties of the steel substrates. Among these surface techniques, laser cladding is considered to be one of the most promising due to the unique properties of wear resistance, metallurgical bonding, low dilution, and the increasing service life of metal parts. Zhan et al. have shown that the appearance of the high-power laser and the wideband scanning device offers a new effective method for the modification of material surface [9]. However, a hard surface will accelerate the wear of its counterpart, and it is ineffective for preventing the strain fatigue of the substrate, which will result in the failure of scuffing [9]. In this case, it is a good way to prepare the solid lubrication on the surface of wear resistance coating [10-12].
As we know, the sulfide FeS is a kind of effective solid lubrication with high melting point and can improve the selflubricating property of materials obviously. Ion sulphurizing technology has been applied to prepare FeS film on the metal surface, which remarkably increased the self-lubricating property [10-12]. However, the studies of the coatings, with the properties of wear resistance and self-lubricating at the same time, prepared by laser cladding and low temperature ion sulfurization technology have not been reported in the literatures.

The goal of this work was to prepare the soft solid lubrication coating on the laser cladding Ni-based layer by means of low temperature ion sulfurization and to examine the microstructure, composition distribution, and properties.

\section{Experimental Procedure}

The samples of 45 steel were heat-treated by quenching and low temperature tempering and machined to the rectangular 
TABLE 1: Chemical composition of 45 steels (wt, \%).

\begin{tabular}{lcccccr}
\hline $\mathrm{C}$ & $\mathrm{Si}$ & $\mathrm{Mn}$ & $\mathrm{P}$ & $\mathrm{Cr}$ & $\mathrm{Ni}$ & \\
\hline $0.42-0.50$ & $0.17-0.37$ & $0.50-0.80$ & $\leq 0.04$ & $\leq 0.25$ & $\leq 0.25$ & Bal. \\
\hline
\end{tabular}

TABLE 2: Chemical composition of Ni55 alloying powder (wt, \%).

\begin{tabular}{lcccccccccc}
\hline C & $\mathrm{Cr}$ & $\mathrm{Fe}$ & $\mathrm{Mn}$ & $\mathrm{Mo}$ & $\mathrm{Al}$ & $\mathrm{Si}$ & $\mathrm{B}$ & $\mathrm{S}$ & $\mathrm{P}$ & $\mathrm{Ni}$ \\
\hline 0.66 & 16.28 & 25.63 & 0.15 & 0.70 & 0.01 & 2.92 & 2.21 & 0.01 & 0.01 & $\mathrm{Bal}$ \\
\hline
\end{tabular}

TABLE 3: Hardness of Ni55 + W laser cladding layer (HRC).

\begin{tabular}{lcccc}
\hline Powders & $\mathrm{Ni} 55+5 \% \mathrm{~W}$ & $\mathrm{Ni} 55+10 \% \mathrm{~W}$ & $\mathrm{Ni} 55+15 \% \mathrm{~W}$ & $\mathrm{Ni55}+20 \% \mathrm{~W}$ \\
\hline Hardness/HRC & 44.7 & 46.5 & 39.3 & 35.8 \\
\hline
\end{tabular}

shape of $45 \mathrm{~mm} \times 45 \mathrm{~mm} \times 10 \mathrm{~mm}$ as the substrate, and the chemical composition is listed in Table 1 . The substrate is composed of ferrite and pearlite with the hardness of $150 \mathrm{HV}_{0.1}$. The laser cladding Ni-based powder is mixed with Ni55 and different percents of pure $W$ powders, and the chemical compositions of Ni55 powder are listed in Table 2. And the cladding powder is preplaced on the samples with the thickness of $1 \mathrm{~mm}$. Laser cladding was performed using a continuous wave $\mathrm{CO}_{2}$ laser. A laser power of $3.5 \mathrm{~kW}$ at the work piece with a beam size of $10 \mathrm{~mm} \times 1 \mathrm{~mm}$ and scanning velocity of $200 \mathrm{~mm} / \mathrm{min}$ was applied. After laser cladding, the surfaces of specimens were polished with the surface roughness $\mathrm{Ra}$ of $0.8 \mu \mathrm{m}$ and all specimens were simultaneously sulfurized in the furnace of low temperature ion sulfurization $\left(300^{\circ} \mathrm{C}\right)$ for $1 \mathrm{~h}, 3 \mathrm{~h}$, and $4 \mathrm{~h}$, respectively.

$\mathrm{X}$-ray diffraction (XRD) was utilized to analyze the phase structures of the laser cladding layer and sulfide composite coating. Atomic force microscope (AFM) and scanning electron microscope (SEM) equipped with EDS were employed to analyze the morphologies of surface and cross section of the sulfide composite coatings. EPMA scanning was carried out to study the distribution of elements within the composite coating. X-ray photoelectron spectroscope (XPS) was used to detect the valence states of the sulfide composite coating.

The friction and wear tests were carried out on a ballon-disc test rig of MMU-5G model. The upper sample was GCr13 steel ball with diameter $4 \mathrm{~mm}$ with the hardness of $60 \mathrm{HRC}$, and the lower samples were specimens treated by laser cladding and laser cladding-ion sulfurizing composite treatment with dimension of $\Phi 43 \mathrm{~mm} \times 5 \mathrm{~mm}$. The wear tests were carried out under dry friction condition and the lubrication condition with number 40 machine oil (without any additives). The kinematic viscosity was $37-43 \mathrm{~mm}^{2} / \mathrm{s}$ at $50^{\circ} \mathrm{C}$ and the velocity of oil supply was $2 \mathrm{~mL} / \mathrm{min}$. The load of $50 \mathrm{~N}$ and a velocity of $50 \mathrm{rpm}$ for $60 \mathrm{~min}$ were chosen to test the variation of friction coefficient with time. The wear conditions were a normal load of $50 \mathrm{~N}$, a sliding speed of $0.63 \mathrm{~m} / \mathrm{s}$, and the test time of $60 \mathrm{~min}$.

\section{Results and Discussion}

3.1. Selection of Process Parameters. In this experiment, the weight percent of pure tungsten powder included in Ni55
TABLE 4: EDS results of the composite coating for different times (atom \%).

\begin{tabular}{cccccccc}
\hline & \multicolumn{7}{c}{ Elements } \\
& $\mathrm{O}$ & $\mathrm{S}$ & $\mathrm{Cr}$ & $\mathrm{Fe}$ & $\mathrm{Ni}$ & $\mathrm{W}$ & $\mathrm{C}$ \\
\hline $1 \mathrm{~h}$ & 15.59 & 2.48 & 9.41 & 34.49 & 9.42 & 5.90 & 22.71 \\
$3 \mathrm{~h}$ & 23.94 & 3.42 & 8.70 & 27.50 & 8.02 & 4.02 & 24.40 \\
$4 \mathrm{~h}$ & 19.95 & 3.56 & 6.98 & 24.74 & 11.56 & 3.37 & 29.84 \\
\hline
\end{tabular}

alloy powder is $5 \%, 10 \%, 15 \%$, and $20 \%$, respectively. And the hardness values of the laser cladding Ni-based coatings are listed in Table 3. It can be seen that the hardness of the cladding coating reaches its maximum of $46.5 \mathrm{HRC}$ at the percent of $10 \% \mathrm{~W}$.

Figure 1 illustrates the morphologies of Ni55 $+10 \% \mathrm{~W}$ sulfide coatings at different sulfurizing times. It can be seen that the increase of sulfurizing time makes the surface of the composite coating darken.

The EDS analysis results of the composite coating with different sulfurizing times were shown in Table 4 . The content of $\mathrm{S}$ element increases gradually with the increment of sulfurizing time, and highest value can reach $3.56 \%$ at the time of $4 \mathrm{~h}$.

\subsection{Microstructures of Laser Cladding Ni55 $+10 \% W$ Coating.} For the range of parameters adopted in the experiments, a dense, uniform, and crack-free structure was obtained. Microstructural examination of the cladding Ni55 $+10 \% \mathrm{~W}$ coating shows that a thin layer of planar growth was present at all interfaces with an extension of around $3 \mu \mathrm{m}-5 \mu \mathrm{m}$ and a combination of columnar dendrites crystals and ultrafine dendritic structure (Figure 2).

The bottom and the middle region show cellular/dendritic structures (Figures 2(a) and 2(b)), while the upper region consists of ultrafine dendrites (Figure 2(c)). The solidification structure of the laser cladding layer mainly depends upon the solid-liquid interface growth rate $R$ and the temperature gradient in the melt $G$. According to the numerical simulation of heat flow process in the molten pool [13], laser cladding is a rapid heating and rapid cooling process, and there exists an extremely high temperature gradient in the laser molten pool. Such variation in temperature results in the variation 


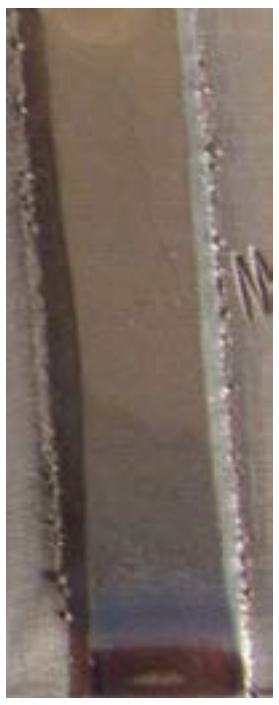

(a)

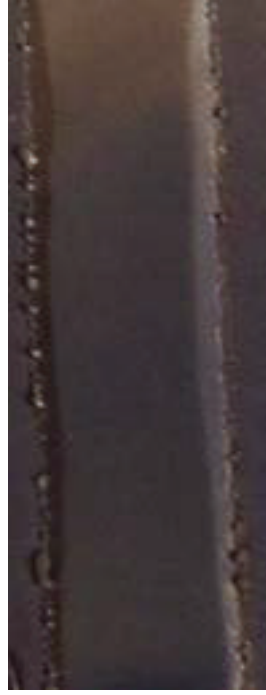

(b)

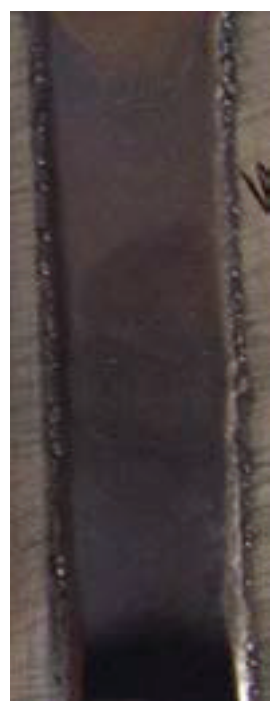

(c)

Figure 1: Macromorphologies of the Ni55 + 10\%W sulfide coatings. (a) $1 \mathrm{~h}$; (b) $3 \mathrm{~h}$; and (c) $4 \mathrm{~h}$.
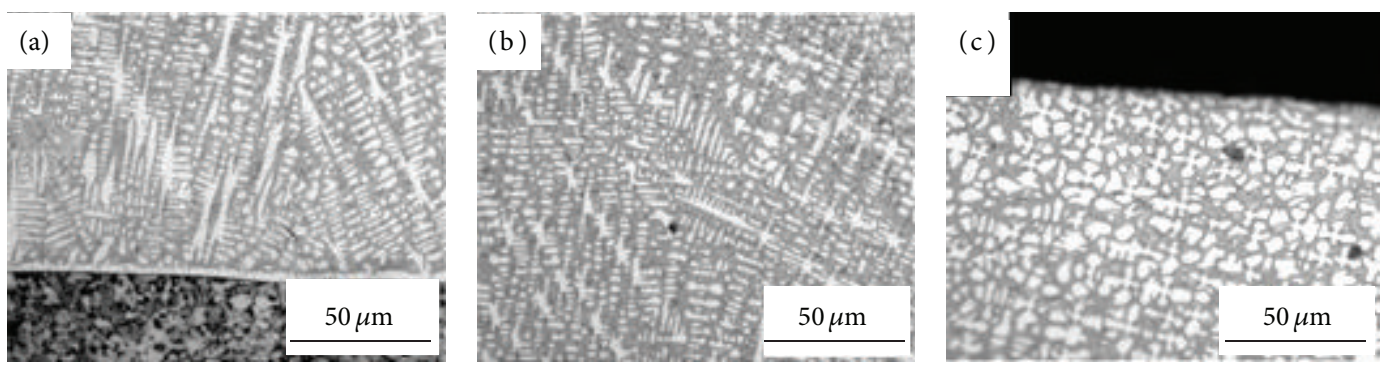

FIGURE 2: Microstructure of Ni55 + 10\%W cladding coating. (a) Bottom region; (b) middle region; and (c) upper region.

in the ratio of temperature gradient $(G)$ to the growth rate $(R)$ during solidification following laser cladding. Thus, the $G / R$ value becomes the controlling factor for the morphology selection. As the $G / R$ ratio changes from its highest value at the bottom to its lowest one on the surface, such variation results in the variation in the degree of constitutional supercooling, leading to a complex solidification structure in the laser cladding coating.

According to the XRD analysis result in Figure 3, the laser cladding Ni55 $+10 \% \mathrm{~W}$ coating is composed of $\gamma$-(Fe, Ni), $\mathrm{M}_{23} \mathrm{C}_{6}$ and WC carbides.

3.3. Phase and Structural Analysis of the Ni55 $+10 \% W$ Sulfide Composite Coating. The phase and structural analysis of the $\mathrm{Ni} 55+10 \% \mathrm{~W}$ sulfurized at $300^{\circ} \mathrm{C}$ for $4 \mathrm{~h}$ were analyzed. The $\mathrm{XRD}$ analysis result in Figure 4 indicates that the composite coating consists of $\gamma$ - $(\mathrm{Fe}, \mathrm{Ni}), \mathrm{M}_{23} \mathrm{C}_{6}$ carbides, $\mathrm{FeS}, \mathrm{FeS}_{2}$, and $\mathrm{WS}_{2}$.

Figure 4 illustrates the surface morphology of the Ni55 + $10 \% \mathrm{~W}$ sulfide composite coating observed under AFM. The 3D morphology in Figure 5(a) reveals the loose and porous characteristics of the composite coating, which is formed with

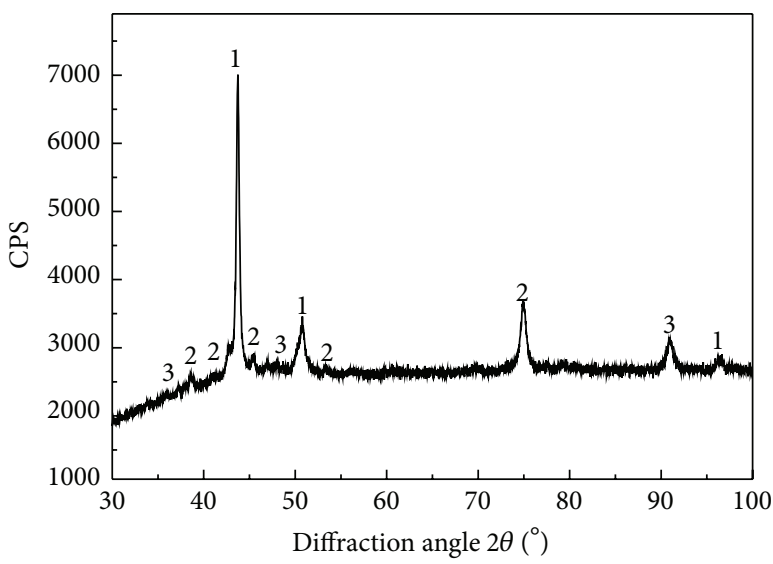
(1) $(\mathrm{Fe}, \mathrm{Ni})$
(2) $\mathrm{Cr}_{23} \mathrm{C}_{6}$
(3) WC

FigURE 3: XRD pattern of the laser cladding Ni55 $+10 \% \mathrm{~W}$ coating.

nanoscale spherical grains. Moreover, the granularity of all grains is less than $100 \mathrm{~nm}$. 


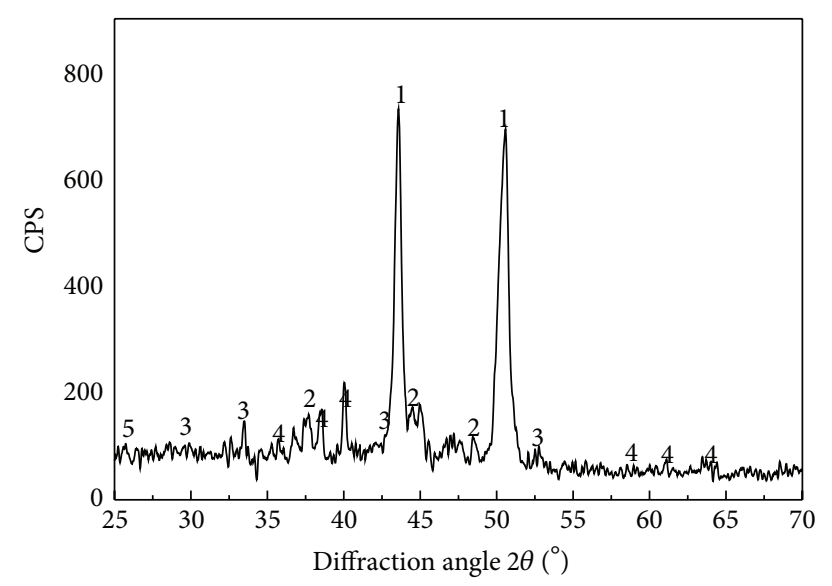
(1) $(\mathrm{Fe}, \mathrm{Ni})$
(4) $\mathrm{WS}_{2}$
(2) $\mathrm{Cr}_{23} \mathrm{C}_{6}$
(5) $\mathrm{FeS}_{2}$
(3) $\mathrm{FeS}$

FIGURE 4: XRD pattern of Ni55 + 10\%W sulfide composite coating.

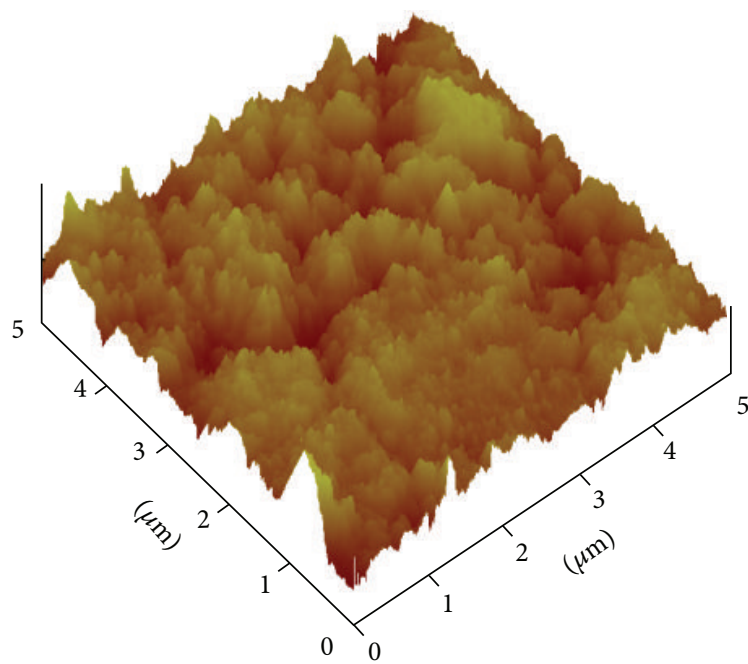

(a)

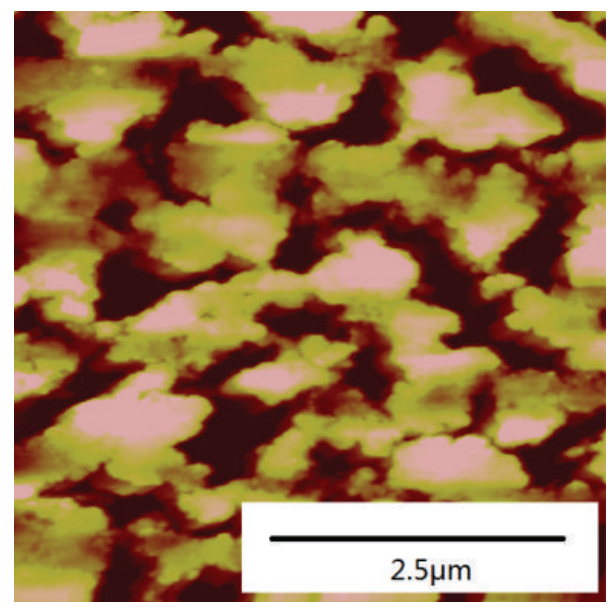

(b)

FIgURE 5: Micromorphology of Ni55 $+10 \% \mathrm{~W}$ sulfide coating (AFM). (a) 3D morphology; (b) 2D morphology.
EPMA scanning analysis results of the Ni55 + 10\%W sulfide composite coating are shown in Figure 6. We can see that the contents of $\mathrm{C}, \mathrm{Fe}, \mathrm{Ni}, \mathrm{B}$, and $\mathrm{Cr}$ elements are high and these elements distribute uniformly. After laser cladding, these elements remain in solid solution in the austenitic matrix, playing a role of solid solution strengthening. Furthermore, the content of $\mathrm{W}$ element in the Ni55 + $10 \% \mathrm{~W}$ sulfide composite coating is high due to the additional introduction of pure W powder. Particularly, S element distributes unevenly resulting from the selective reaction with Fe element and $\mathrm{W}$ element, such as the formations of $\mathrm{FeS}, \mathrm{FeS}_{2}$, and $\mathrm{WS}_{2}$.

Figure $7(\mathrm{a})$ is the cross-sectional morphology of the $\mathrm{Ni} 55+10 \% \mathrm{~W}$ sulfide composite coating. It can be seen that the width of the sulfide composite coating is about $2 \mu \mathrm{m}$. According to the distribution of S element along depth direction, it is clear that no transition zone was found between the composite layer and the cladding layer (Figure 7(b)).

XPS analysis was introduced to study the chemical composition of the Ni55 $+10 \% \mathrm{~W}$ sulfide composite coating etched for different times, and the results were listed in Table 5 and the atomic percents were shown in Figure 8. We can see that with the etched time increase the content of S element increases and then decreases.

The valence states of $\mathrm{Fe}, \mathrm{S}$, and $\mathrm{W}$ in the Ni55 + 10\%W sulfide composite coating etched for 300 s were analyzed by XPS, as shown in Figure 9. It could be concluded that there were four phases present in the sulfide composite coating. One was dominant single substance $\mathrm{Fe}$, and the other phases were solid lubricants $\mathrm{FeS}, \mathrm{WS}_{2}$, and $\mathrm{FeS}_{2}$, which is consistent with the XRD result. Both FeS and $\mathrm{FeS}_{2}$ were produced, but only FeS acts as the solid lubricant, because $\mathrm{FeS}_{2}$ does not possess the close-packed hexagonal structure. Owing to more content of tungsten, the solid lubrication phase of $\mathrm{WS}_{2}$ was also formed in sulfide layer of the Ni55 $+10 \% \mathrm{~W}$ cladding coating. As shown in Figure 9(a), the strong peaks of Fe appear near the binding energies $706.5 \mathrm{eV}, 707 \mathrm{eV}$, and $709.7 \mathrm{eV}$, respectively. According to the standard pattern of electron binding energy of Fe element [14-16], the strong peak near $706.5 \mathrm{eV}$ is corresponding to the $\mathrm{Fe}^{2+}$ in $\mathrm{FeS}_{2}$ and the strong peak near $709.7 \mathrm{eV}$ is assigned to the $\mathrm{Fe}^{2+}$ in $\mathrm{FeS}$, while the strongest peak at $707 \mathrm{eV}$ is contributed by the monoatomic Fe. In addition, the peaks near $161.5 \mathrm{eV}$ and $161.7 \mathrm{eV}$ shown in Figure 10(b) are corresponding to the $\mathrm{S}^{2-}$ in $\mathrm{FeS}$, the peaks at $162.1 \mathrm{eV}$ are identified as the $\mathrm{S}^{-1}$ in $\mathrm{FeS}_{2}$, and the peaks near $162.4 \mathrm{eV}$ and $162.9 \mathrm{eV}$ are assigned to the $\mathrm{S}^{-1}$ in $\mathrm{WS}_{2}$. It means that, besides FeS and $\mathrm{WS}_{2}$, a small quantity of fragile $\mathrm{FeS}_{2}$ with nonlubricity is also formed on the surface of the laser cladding-ion sulfurizing composite coating due to the surplus $\mathrm{S}$ atoms on the surface.

3.4. Friction Coefficient and Mass Loss. Figure 9 shows the friction coefficients of the $\mathrm{Ni} 55+10 \% \mathrm{~W}$ cladding coating and the $\mathrm{Ni} 55+10 \% \mathrm{~W}$ sulfide composite coating under the conditions of dry and oil lubrication. As it can be seen, the sulfurized Ni55 $+\mathrm{W}$ coating possesses lower friction coefficient under the conditions of dry (Figure 10(a)) and oil (Figure 10(b)) lubrication, and the lower friction coefficient 
TABLE 5: Chemical composition of Ni55 $+10 \% \mathrm{~W}$ sulfide composite coating etched for different times.

\begin{tabular}{|c|c|c|c|c|c|c|c|c|}
\hline \multirow{2}{*}{ Etched time/s } & \multicolumn{8}{|c|}{ Atomic percent (\%) } \\
\hline & Cls & O1s & $\mathrm{Fe} 2 \mathrm{p}$ & S2p & $\mathrm{Cr} 2 \mathrm{p}$ & $\mathrm{Ni} 2 \mathrm{p}$ & W4f & $\operatorname{Si} 2 p$ \\
\hline 0 & 65.6414 & 26.0216 & 2.65498 & 2.02515 & 0.472699 & 0.631961 & 0.403379 & 1.9669 \\
\hline 150 & 17.9697 & 31.0302 & 26.4168 & 7.64461 & 3.29902 & 4.23549 & 5.87352 & 3.44132 \\
\hline 300 & 14.5179 & 21.8039 & 30.0488 & 7.03203 & 4.88831 & 8.6998 & 9.03891 & 3.86298 \\
\hline 900 & 8.66824 & 6.7955 & 41.0852 & 3.46824 & 7.3243 & 16.8425 & 12.5326 & 3.18362 \\
\hline 1500 & 8.40491 & 3.5191 & 42.7755 & 2.36077 & 8.54908 & 18.1784 & 13.8193 & 2.2815 \\
\hline
\end{tabular}

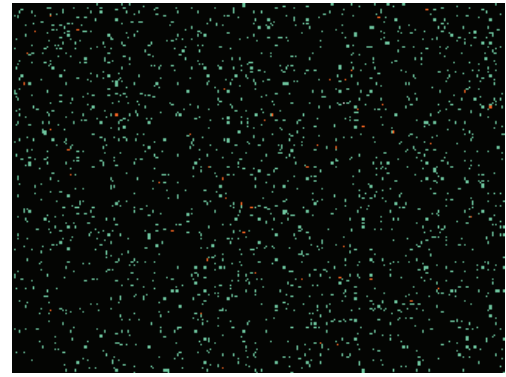

B $-20 \mu \mathrm{m}$

(a)

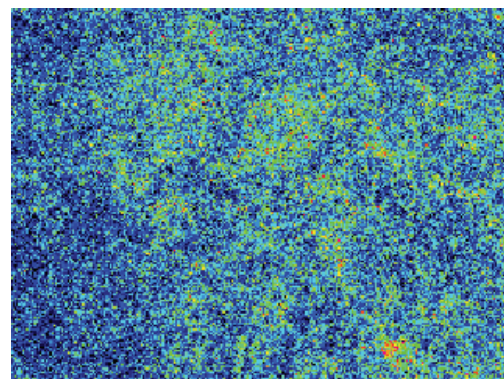

C $-20 \mu \mathrm{m}$

(d)

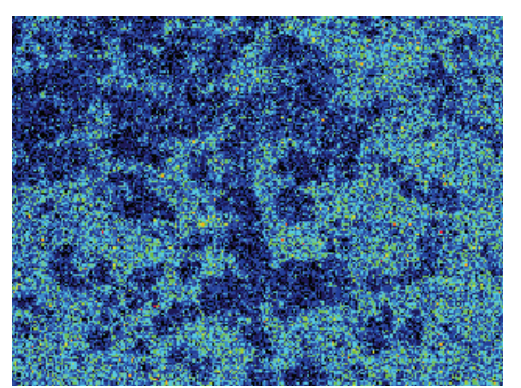

$\mathrm{S}-20 \mu \mathrm{m}$

(b)

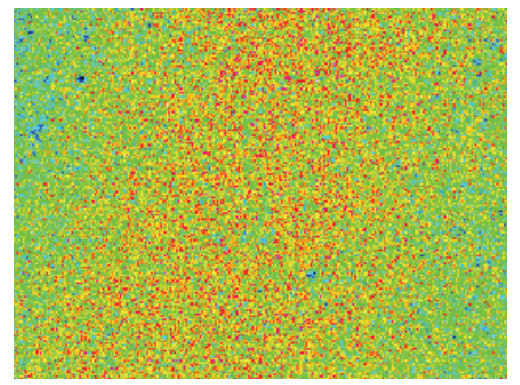

$\mathrm{Fe}-20 \mu \mathrm{m}$

(e)

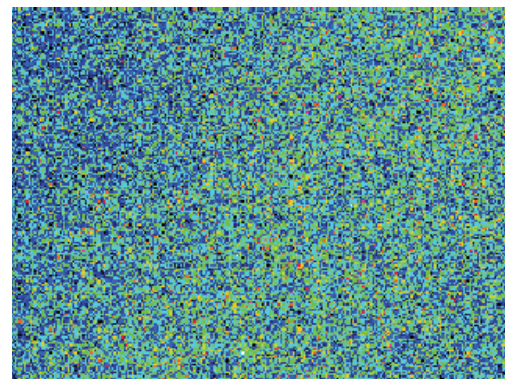

$\mathrm{W}-20 \mu \mathrm{m}$

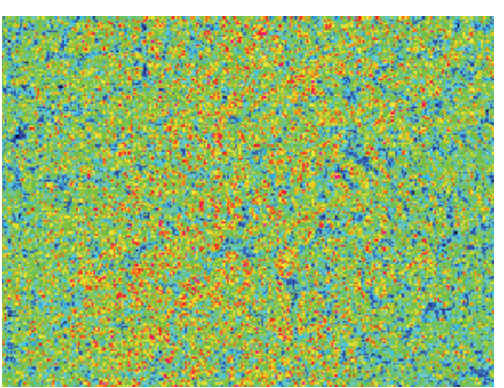

$\mathrm{Ni}-20 \mu \mathrm{m}$

(c)

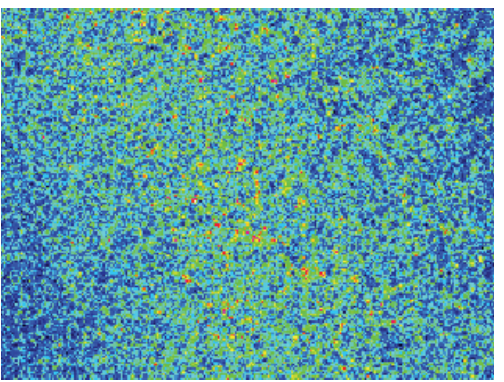

$\mathrm{W}-20 \mu \mathrm{m}$

(f)

(g)

Figure 6: EMPA scanning analysis of Ni55 + 10\%W sulfide coating. (a) B; (b) S; (c) Ni; (d) C; (e) Fe; (f) W; and (g) Cr.

for two coatings appears under oil lubrication. The friction coefficient of the Ni55 $+10 \% \mathrm{~W}$ cladding coating is about 0.9 and it reduced to 0.65 for the sulfide composite coating under dry condition. However, under the condition of oil lubrication, the friction coefficient of the $\mathrm{Ni} 55+10 \% \mathrm{~W}$ sulfide composite coating is 0.075 , which is reduced by $40 \%$ compared with the $\mathrm{Ni55}+10 \% \mathrm{~W}$ cladding coating.
Particularly, the variation of friction coefficient of the Ni55 + $10 \% \mathrm{~W}$ sulfide composite coating was very smooth, indicating that under oil lubrication the composite coating was sliding at a quite steady state.

According to the results shown in Figure 11, the mass losses of the Ni55 +10\%W sulfide composite coating are much lower than those of laser cladding Ni55 $+10 \% \mathrm{~W}$ coating. 


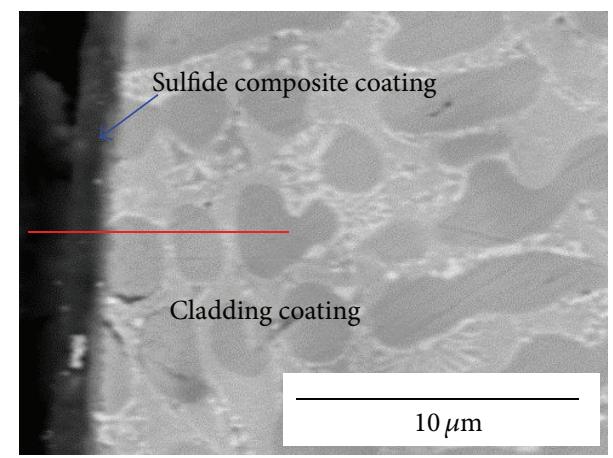

(a)

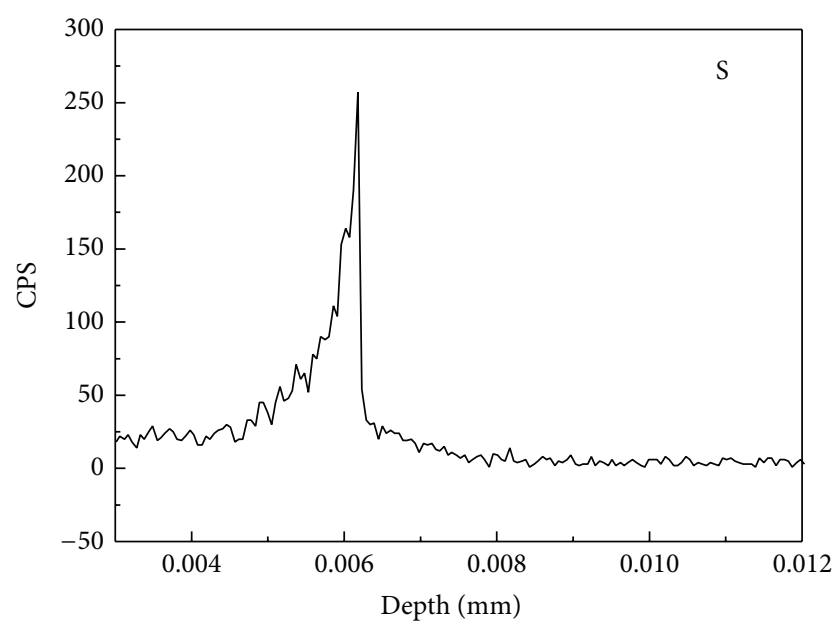

(b)

Figure 7: (a) Cross-sectional morphology of the Ni55 + 10\%W sulfide composite coating; (b) the distribution of S element along depth direction.

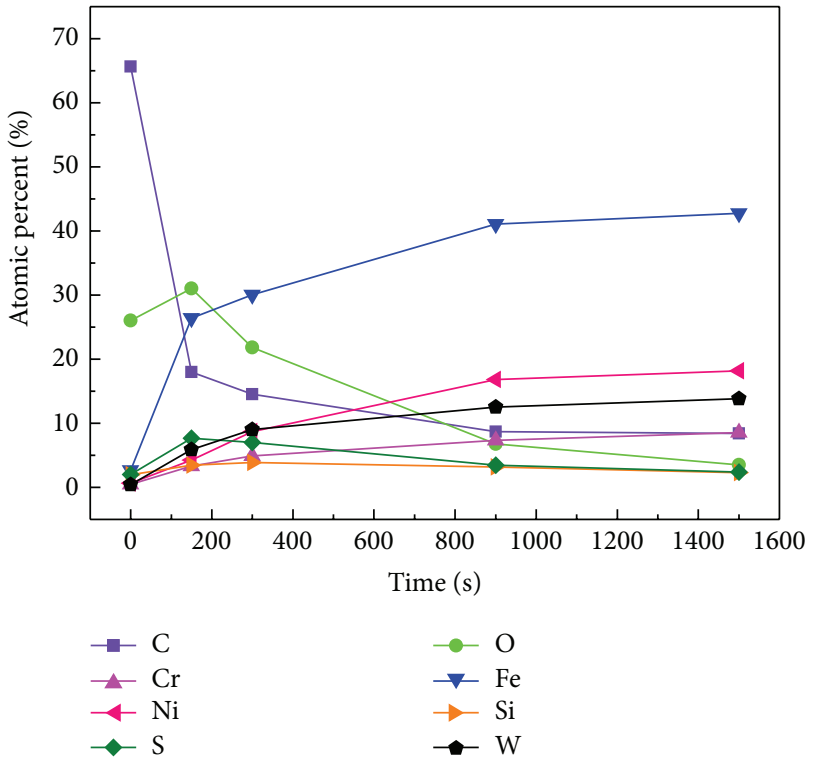

FIGURE 8: Atomic percents of elements as etched time.

These results indicate that the Ni55 $+10 \% \mathrm{~W}$ sulfide composite coating reflects better wear resistance than the laser cladding coating, and it is feasible to improve the wear resistance of Ni-based cladding coating by ion sulfurization processing.

According to the tribological theory, an ideal friction surface should be soft at the surface, possessing excellent lubricating property, and hard at subsurface; that is, the hard substrate can give a sufficient support to the lubrication layer and keep a longer time of its effect. The hardness of sulfuration layer is very low, about 50-100 HV [17], while the hardness of the Ni55 $+10 \% \mathrm{~W}$ cladding coating is high, reaching $46.5 \mathrm{HRC}$, which is helpful for the improving of the wear resistance.
In addition, the Ni55 $+10 \% \mathrm{~W}$ sulfide composite coating is composed of $\gamma$ - $(\mathrm{Fe}, \mathrm{Ni}), \mathrm{M}_{23} \mathrm{C}_{6}$ carbides, $\mathrm{FeS}, \mathrm{FeS}_{2}$, and $\mathrm{WS}_{2}$, and the FeS and $\mathrm{WS}_{2}$ are the typical solid lubricant. As we know, similar to $\mathrm{MoS}_{2}$ and graphite, $\mathrm{WS}_{2}$ has closepacked hexagonal layered structure, and the lattice constants are $a=0.318 \mathrm{~nm}$ and $c=1.25 \mathrm{~nm}$. Each tungsten atom connects two sulfur atoms and tungsten atom and sulfur atom are connected by strong chemical bond, while sulfur atoms are connected by weak molecule bond. According to the investigations in [18], the friction coefficient of $\mathrm{WS}_{2}$ is very low and it can protect metal surface from adhesion. Moreover, the crystal lattice of FeS is a close-packed hexagonal structure, and lattice constants are $a=0.597 \mathrm{~nm}$ and $c=1.174 \mathrm{~nm}$. It can easily slip along close-packed plane, and the plastic rheology is good and the melting point is as high as $1100^{\circ} \mathrm{C}$. When the friction-pair is sliding mutually, the partial FeS and $\mathrm{WS}_{2}$ films are adhered to the surface of steel ball and filled in its valley so that its surface is also covered with a solid lubrication film. The self-acting transfer of the solid lubricant between the friction-pair improves the lubrication condition [19]. So the Ni55 $+10 \% \mathrm{~W}$ sulfide composite coating can improve remarkably the properties of wear resistance and antifriction.

\section{Conclusions}

(1) Laser cladding was applied to prepare the Ni-based coatings and the maximum hardness of $46.5 \mathrm{HRC}$ was obtained when the percent of pure $\mathrm{W}$ powder was $10 \%$.

(2) The laser cladding Ni55 $+10 \% \mathrm{~W}$ coating is composed of a thin layer of planar growth and a combination of columnar dendrites crystals and ultrafine dendritic structure.

(3) After ion sulfurization, the loose and porous composite coating is formed with nanospherical grains and 


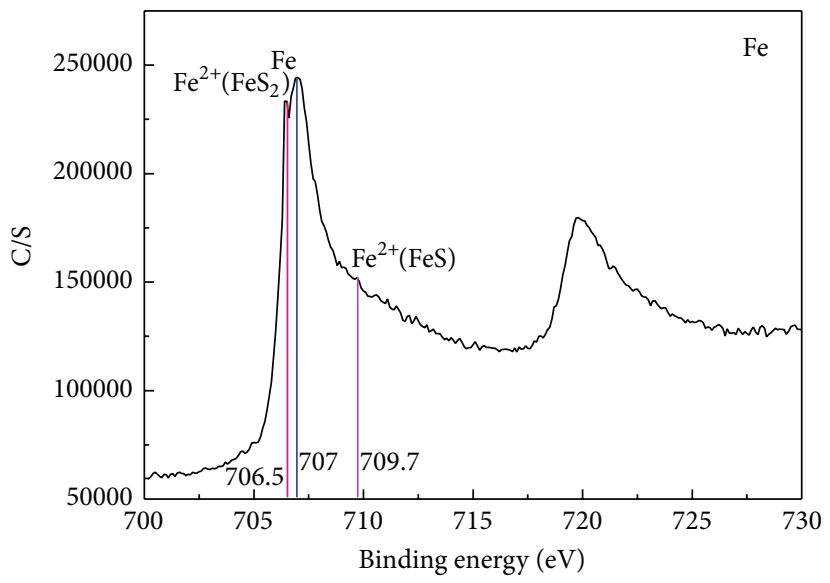

(a)

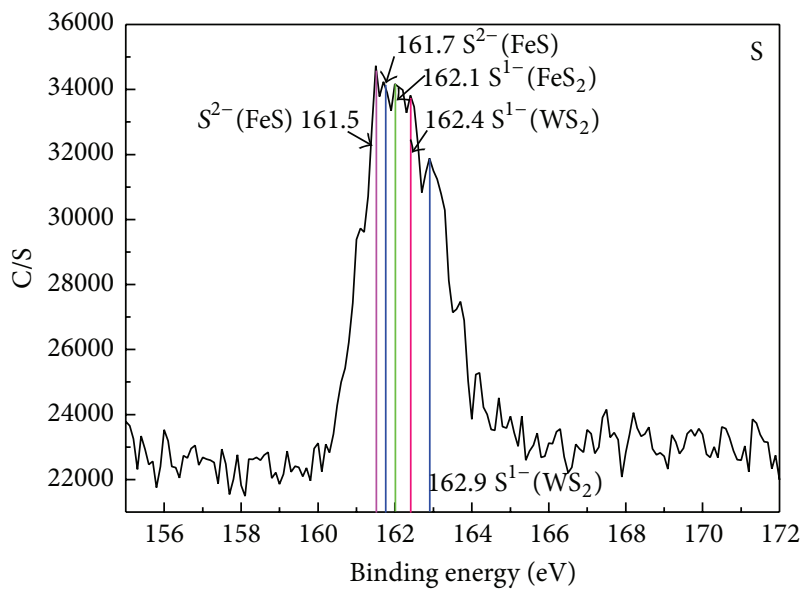

(b)

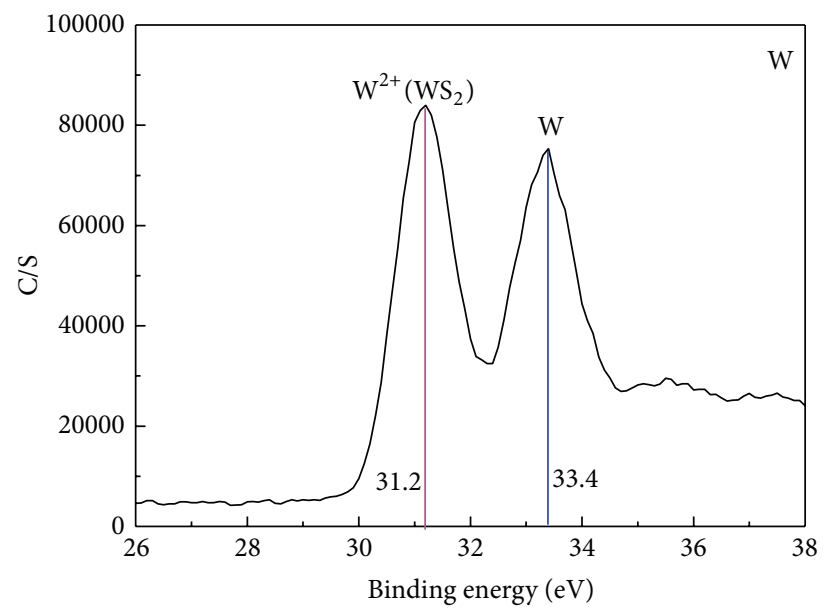

(c)

FIGURE 9: XPS analysis of the Ni55 + 10\%W sulfide composite coating. (a) Fe; (b) S; and (c) W.

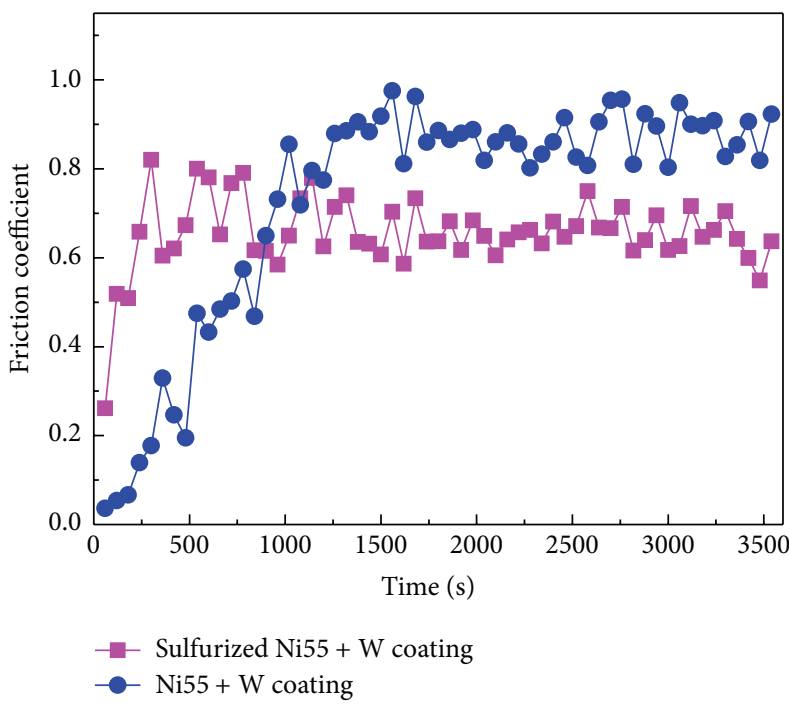

(a)

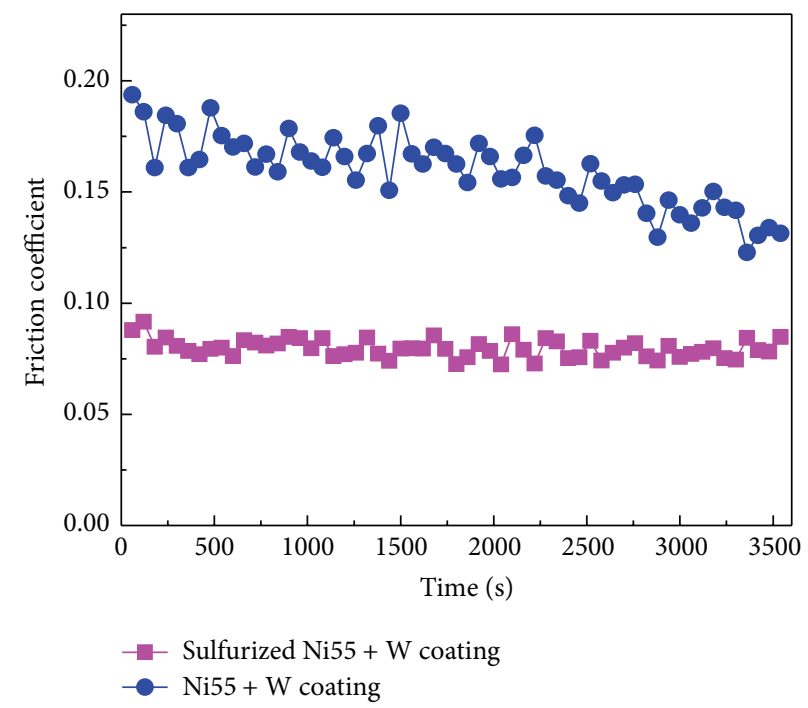

(b)

FIGURE 10: Friction coefficient curves of different coatings: (a) dry friction; (b) oil lubrication. 

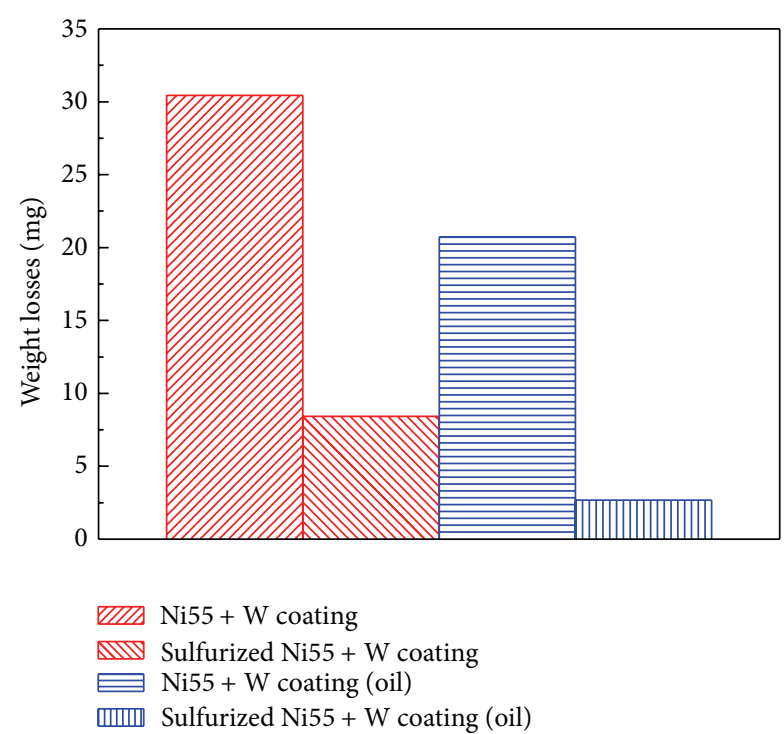

FIGURE 11: Weight losses of different coatings.

the granularity of all grains is less than $100 \mathrm{~nm}$. And the $\mathrm{Ni55}+10 \% \mathrm{~W}$ sulfide composite coating consists of $\gamma$-(Fe, $\mathrm{Ni}), \mathrm{M}_{23} \mathrm{C}_{6}$ carbides, FeS, $\mathrm{FeS}_{2}$, and $\mathrm{WS}_{2}$.

(4) The Ni55 $+10 \% \mathrm{~W}$ sulfide composite coating reflects better wear resistance than the laser cladding coating, and the friction coefficient and mass losses under the conditions of dry and oil lubrication are lower than those of $\mathrm{Ni} 55+10 \% \mathrm{~W}$ cladding coating.

\section{Conflict of Interests}

The authors declare that there is no conflict of interests regarding the publication of this paper.

\section{Acknowledgments}

The authors would like to acknowledge the supports from Open Fund (OGE201403-04) of Key Laboratory of Oil \& Gas Equipment, Ministry of Education (Southwest Petroleum University), the National Natural Science Foundation of China (51179202), and the Natural Science Foundation of Shandong Province (ZR2014EEQ037).

\section{References}

[1] X. You, C. Zhang, X. Song, M. Huang, and J. Ma, "Microstructure evolution of WC/steel composite by laser surface remelting," Applied Surface Science, vol. 253, no. 9, pp. 4409-4414, 2007.

[2] Y. Wang, M. Y. Li, and B. Han, "Influence of secondary carbides precipitation and transformation on the secondary hardening of laser melted high chromium steel," Journal of Materials Science, vol. 45, no. 13, pp. 3442-3447, 2010.

[3] R. Colaco, E. Gordo, E. M. Ruiz-Navas, M. Otasevic, and R. Vilar, "A comparative study of the wear behaviour of sintered and laser surface melted AISI M42 high speed steel diluted with iron," Wear, vol. 260, no. 9-10, pp. 949-956, 2006.
[4] C.-J. Chen, X. Xu, Q. Cao, M. Zhang, Q. Chang, and S. Zhang, "Laser surface cladding of plastic-molded steel $718 \mathrm{H}$ by CoCrMo alloy," Journal of Materials Engineering and Performance, vol. 21, no. 6, pp. 946-950, 2012.

[5] Y. Altunpak, H. Akbulut, and F. Üstel, "The effect of plasma spraying on the microstructure and aging kinetics of the AlSi Matrix Alloy and Al-Si/SiC composites," Journal of Materials Engineering and Performance, vol. 19, no. 1, pp. 116-122, 2010.

[6] A. Nusair Khan and J. Lu, "Manipulation of air plasma spraying parameters for the production of ceramic coatings," Journal of Materials Processing Technology, vol. 209, no. 5, pp. 2508-2514, 2009.

[7] X. Mei, S. Hao, T. Ma et al., "Microstructure and wear resistance of high-speed steel treated with intense pulsed ion beam," Nuclear Instruments and Methods in Physics Research B, vol. 239, no. 3, pp. 152-158, 2005.

[8] L. Xiao, D. Yan, J. He et al., "Nanostructured TiN coating prepared by reactive plasma spraying in atmosphere," Applied Surface Science, vol. 253, no. 18, pp. 7535-7539, 2007.

[9] H. Zhan, Y. Wang, C. Li et al., "Computational and experimental study of a melt-hardened zone on a roller modified by wideband laser treatment," Optics \& Laser Technology, vol. 41, no. 3, pp. 251-257, 2009.

[10] G. Z. Ma, B. S. Xu, H. D. Wang, G. L. Li, and S. Zhang, "The lowtemperature ion sulfurizing technology and its applications," Physics Procedia, vol. 50, pp. 131-138, 2013.

[11] H. D. Wang, D. M. Zhuang, K. L. Wang, and J. J. Liu, "Antiscuffing properties of ion sulfide layers on three hard steels," Wear, vol. 253, no. 11-12, pp. 1207-1213, 2002.

[12] H.-D. Wang, B.-S. Xu, J.-J. Liu, and D.-M. Zhuang, "Characterization and tribological properties of plasma sprayed FeS solid lubrication coatings," Materials Characterization, vol. 55, no. 1, pp. 43-49, 2005.

[13] A. Farnia, F. M. Ghaini, V. Ocelík, and J. T. M. de Hosson, "Microstructural characterization of Co-based coating deposited by low power pulse laser cladding," Journal of Materials Science, vol. 48, no. 6, pp. 2714-2723, 2013.

[14] G.-Z. Ma, B.-S. Xu, H.-D. Wang, and H.-J. Si, "Effects of surface nanocrystallization pretreatment on low-temperature ion sulfurization behavior of 1Cr18Ni9Ti stainless steel," Applied Surface Science, vol. 257, no. 4, pp. 1204-1210, 2010.

[15] http://srdata.nist.gov/xps/EngElmSrchQuery.aspx?EType=PE\& CSOpt=Retri_ex_dat\&Elm $=$ O.

[16] http://www.lasurface.com/database/elementxps.php.

[17] S. G. Yuan and J. C. Xiao, "The wear-resistance and antiscuffing of steel after low temperature ion sulfuration," Metal Heat Treating, pp. 45-48, 1985 (Chinese).

[18] H. Wang, B. Xu, and J. Liu, Micro and Nano Sulfide Solid Lubrication, Science Press, Beijing, China, 2012.

[19] H.-D. Wang, D.-M. Zhuang, K.-L. Wang, and J.-J. Liu, "The comparison on tribological properties of ion sulfuration steels under oil lubrication," Materials Letters, vol. 57, no. 15, pp. 22252232, 2003. 

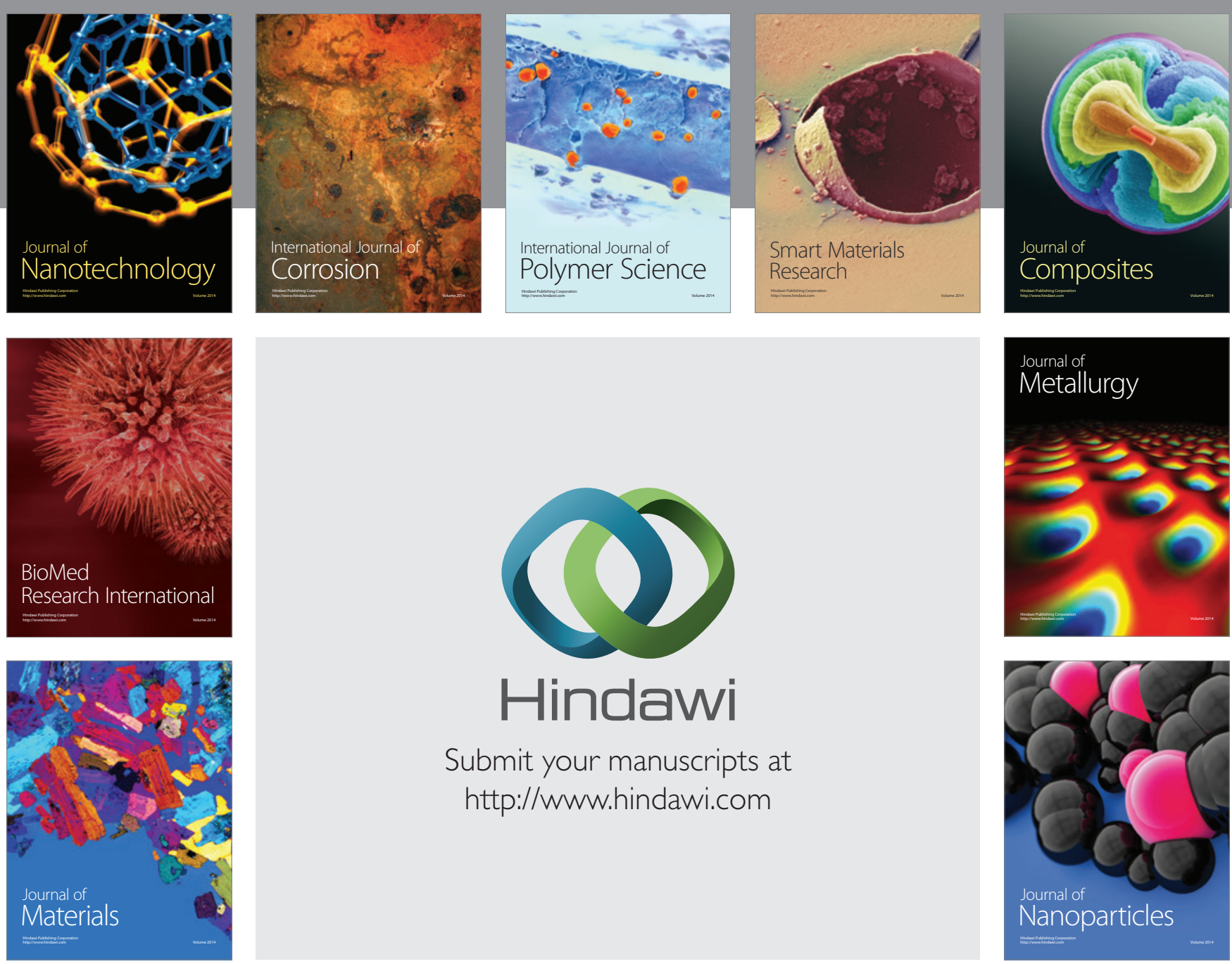

Submit your manuscripts at http://www.hindawi.com
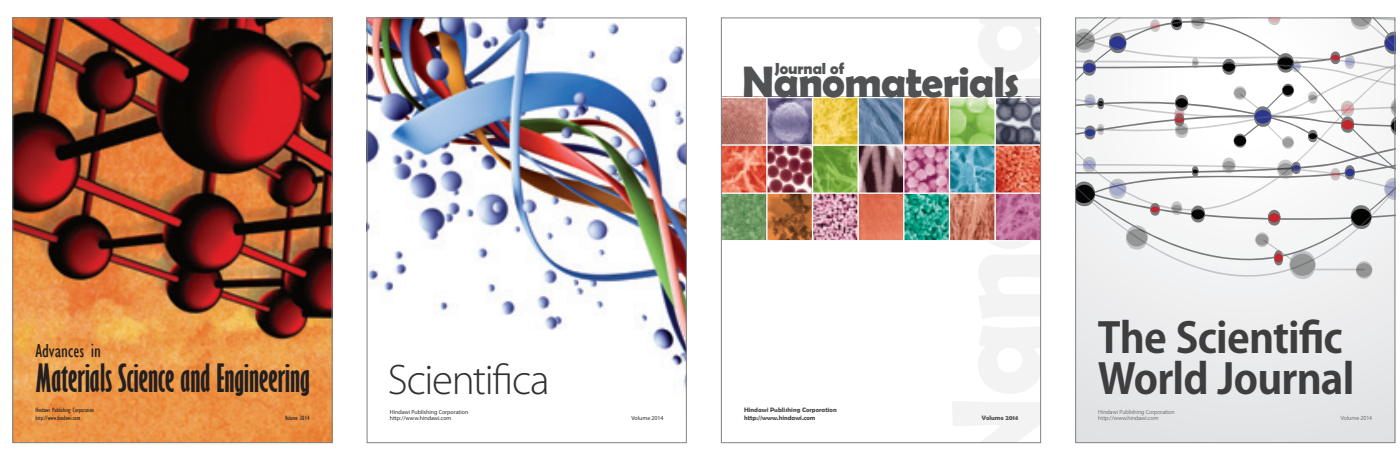

\section{The Scientific World Journal}
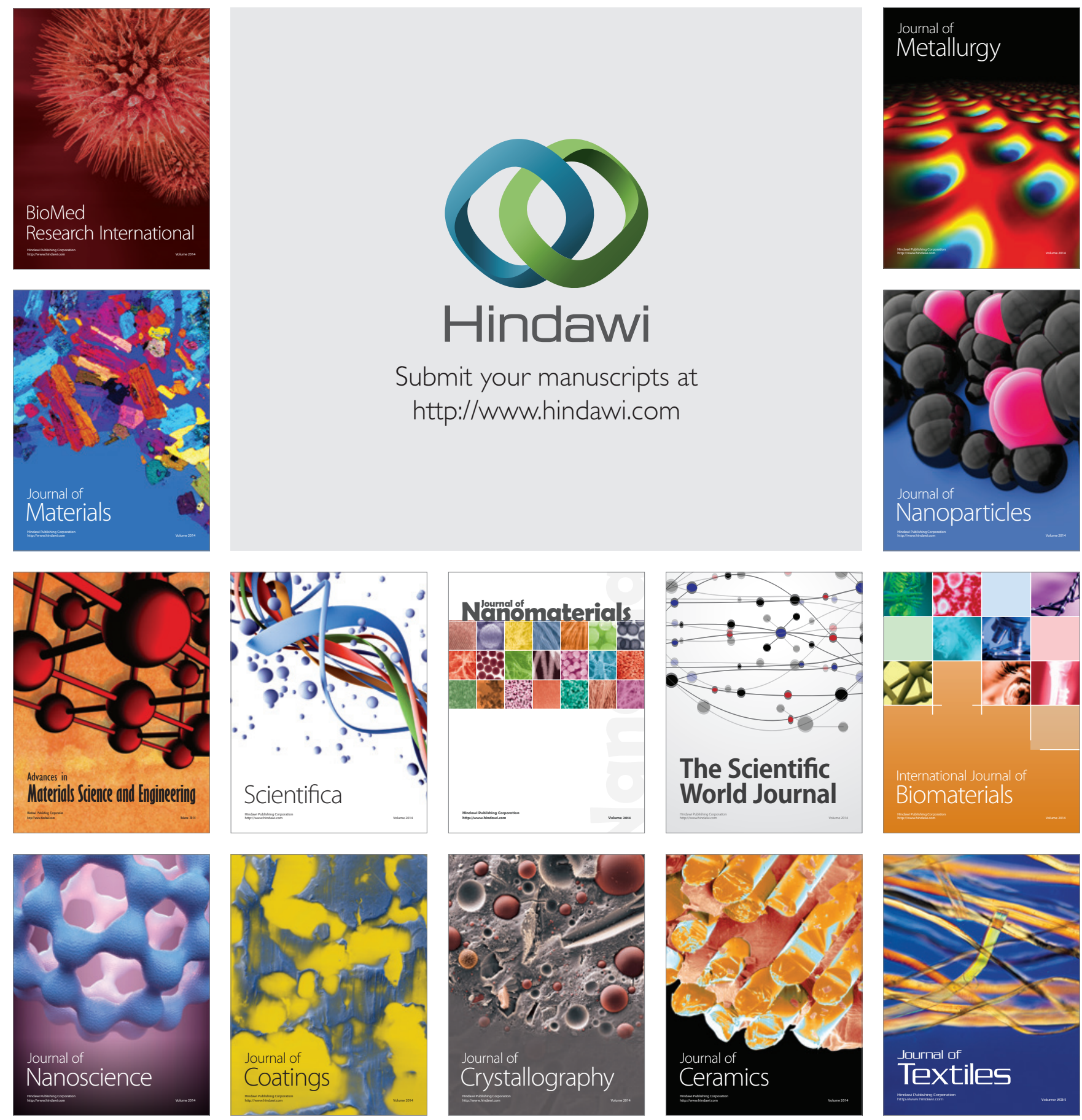